\title{
Visualização e representação espaciais no ensino de Geomorfologia
}

\author{
Carla Juscélia de Oliveira Souza \\ Depto. Geociências, Univ. Fed. São João del-Rei - UFSJ \\ Campus Tancredo Neves, Av. Visc. Rio Preto, s/n.36301-360, \\ São João del-Rei, MG \\ carlaju@ufsj.edu.br \\ Roberto Célio Valadão \\ IInst. Geociências, Univ. Fed. Minas Gerais - UFMG \\ Av. Pres. Antônio Carlos, 6627, Pampulha, 31270-901 \\ Belo Horizonte, MG \\ valadao@ufmg.br
}

\begin{abstract}
VISUALIZATION AND REPRESENTATION OF SPACE IN THE TEACHING OF GEOMORPHOLOGY. Graphic language is an important resource in teaching and learning of Geomorphology contents. Block diagrams, topographical, geological and geomorphological maps and remote sensing images are commonly used as resources. The understanding and use of these resources are one of the skills needed in studies of Geomorphology. Nevertheless, there are difficulties between students with the use of those resources. The difficulties stem from the lack of spatial skills and conceptual representation, which unfold in trouble cartographic and spatial visualization. For a person to perform the identification of landforms on topographic map, he/she must first be able to decode common symbols of the cartographic language and to recognize the ways by which the concepts are represented. Representation and spatial visualization comprise the interaction of various skills and knowledge, which depends from external and internal dimensions inherent for human beings. Citation: Souza C.J.0., Valadão R.C. 2013. Visualização e representação espaciais no ensino de geomorfologia. Terræ Didatica, 9(2):105-113. $<$ http://www.ige.unicamp.br/terraedidatica/>.
\end{abstract}

KEYWORDS: Skills, representation, space visualization, Geomorphology

RESUMO A Geomorfologia emprega imagens como recurso fundamental no ensino-aprendizagem de temáticas referentes ao relevo. Os recursos incluem blocos-diagramas, cartas topográficas, mapas geomorfológicos e geológicos e imagens obtidas por sensores remotos. A compreensão e uso dos recursos constituem habilidades essenciais ao processo de construção do conhecimento geomorfológico. Apesar disso, verificam-se entre graduandos dificuldades com o emprego dos referidos recursos, que decorrem e se relacionam à falta de habilidades espacial, conceitual e de representação e se desdobram, por sua vez, em dificuldades cartográficas e de visualização espacial. Para o sujeito realizar a identificação das formas de relevo, em uma carta topográfica, deve antes ser capaz de decodificar os símbolos comuns na linguagem cartográfica, bem como conhecer conceitualmente as formas representadas. A representação e a visualização espacial compreendem a interação de habilidades e conhecimentos, que interagem a partir da dimensão externa e interna inerente aos seres humanos.

PALAVRAS-CHAVE: Habilidades, representação, visualização espacial, Geomorfologia. 


\section{Introdução}

Os estudos geomorfológicos são comumente conduzidos a partir da observação direta, in loco, durante trabalhos em campo e, complementarmente, por meio da observação indireta, mediante leitura de cartas e mapas topográficos, geológicos e geomorfológicos, blocos-diagramas, maquetes e de outras formas imagéticas, tais como fotografias aéreas e imagens orbitais. Nas modalidades de formação acadêmica em que a construção do conhecimento geomorfológico é incorporada ao currículo como elemento importante ao exercício profissional futuro do graduando, os variados recursos imagéticos adquirem especificidade quanto à semiótica e à habilidade necessária ao sujeito observador. O sujeito deverá ser capaz de decodificar símbolos, relacionar significante e significado, com a finalidade de identificar, analisar e interpretar os elementos registrados referentes ao relevo nas mais diversas perspectivas temporais e espaciais.

Este artigo se insere nesse contexto, com o objetivo de analisar o desempenho de estudantes de graduação durante o processo de construção de conhecimento geomorfológico, com ênfase no exercício de habilidades associadas às representações imagéticas, consequentemente à visualização espacial de formas de relevo. Foram pesquisados os desempenhos de vinte e oito graduandos da Universidade Federal de Minas Gerais, no Instituto de Geociências, matriculados em duas disciplinas distintas - Geomorfologia e Geomorfologia das Áreas Intertropicais - ofertadas em semestres consecutivos. No processo de ensino e aprendizagem da Geomorfologia, nessas disciplinas, a linguagem imagética está fortemente presente em livros-textos, nas mais diversas temáticas abordadas e, ainda, nas atividades práticas efetivadas em sala de aula e fora dela. Portanto, pensar no conhecimento, nas dificuldades e na competência dos graduandos no trato de conteúdos geomorfológicos implicou conhecer o desempenho dos mesmos com as representações imagéticas, notadamente aquelas bidimensionais, como cartas topográficas e croquis.

Para pensar e discutir as habilidades de representação adotou-se, à conta de aporte teórico, autores como Oliveira (1977), Piaget e Inhelder (1993) e Almeida (1994). Buscou-se, também, apoio em trabalhos que contemplam a temática representação e visualização em geociências, como Kali e Orion (1996), Libarkin e Brick (2002), Kastens (2004), Seabra e Santos (2004) e Ishikawa e Kastens (2005).
A construção de parâmetros qualitativos de análise do desempenho apresentado pelos sujeitos da pesquisa foi subsidiada em resultados de pesquisas que tratam de princípios das relações espaciais - topológica, projetiva e euclidiana - discutidos por Piaget, a exemplo de Oliveira (1977), Almeida (1994) e Viana (2000, 2005).

Vale ressaltar que, em trabalho anterior, Souza (2009) considerou as habilidades dos mesmos sujeitos aqui tratados no que se refere à representação de formas fluviais, em perfil e em planta, ao trabalho com blocos-diagramas e a geometria de figuras planas e sólidas. Para o estudo das figuras geométricas, essa autora desenvolveu um teste com base nos níveis de entendimento geométrico, segundo o modelo de Van Hiele (1986). No presente artigo são feitas menções a esses níveis, mas não são apresentados e discutidos os procedimentos e resultados alcançados por Souza (2009). Cada tipo de representação considerado pela autora permitiu verificar que os sujeitos, da pesquisa, que apresentavam bom desempenho nas representações demonstravam, também, razoável desempenho com os conteúdos de geomorfologia e vice-versa, com raras exceções. Importante salientar que, na referida pesquisa foram investigados, também, a concepção dos alunos sobre relevo e geomorfologia, os conceitos-chave desse campo de conhecimento e a compreensão e uso dos mesmos pelos graduandos.

\section{Linguagem Imagética na Geomorfologia}

O universo das imagens compreende dois domínios: o das imagens, como representações visuais, como desenhos, pinturas, gravuras, fotografias etc. e o do domínio imaterial das imagens nas mentes, como visões, imaginações, esquemas e modelos, como representações mentais (Santaella e Nöth 1999). Ambos os domínios não existem separados. Notadamente na geomorfologia, essas representações visuais espaciais se referem, sobretudo à carta topográfica, aos blocos-diagramas e aos perfis topográficos e geológicos, àquelas mais presentes no ensino da Geomorfologia. A carta topográfica, como representação visual, bidimensional da superfície do terreno, assim como os mapas geomorfológicos e geológicos remetem, também, ao conhecimento cartográfico, enquanto os blocos-diagramas remetem, a princípio, às formas geométricas tridimensionais. Ambos, mapas e blocos, constituem recursos da categoria estática 
de visualização (Libarkin e Brick 2002).

Durante o uso das representações, como os mapas, os símbolos devem ser decodificados e interpretados, para que, então as formas possam ser visualizadas. De acordo com Almeida e Passini (1994, p.13), "O mapa funciona como um sistema de signos que lhe permite usar um recurso externo à sua memória, com alto poder de representação e sintetização". Cada objeto do real tem suas propriedades visuais particulares, que permitem ao sujeito percebê-las no real por meio da forma, volume, tamanho e representá-las utilizando-se da linha, da textura, do arranjo no espaço. Os elementos e o arranjo dão à representação uma estrutura, uma organização dos símbolos no papel. Dessa maneira, da combinação das propriedades visuais, dos significados e da relação espacial dos objetos, o sujeito observa, decodifica, percebe, reconhece e analisa de acordo com o seu conhecimento, sua capacidade de selecionar e operar essas variáveis.

As linhas - símbolos - em uma carta topográfica são concebidas, conceitualmente, como curvas de nível (Figs. 1 e 2). Elas se referem às linhas imaginárias de planos geométricos sobrepostos que, em conjunto, compõem uma superfície topográfica, com suas alturas e suas rupturas no terreno, conforme mostrado na Figura 1. A imagem presente

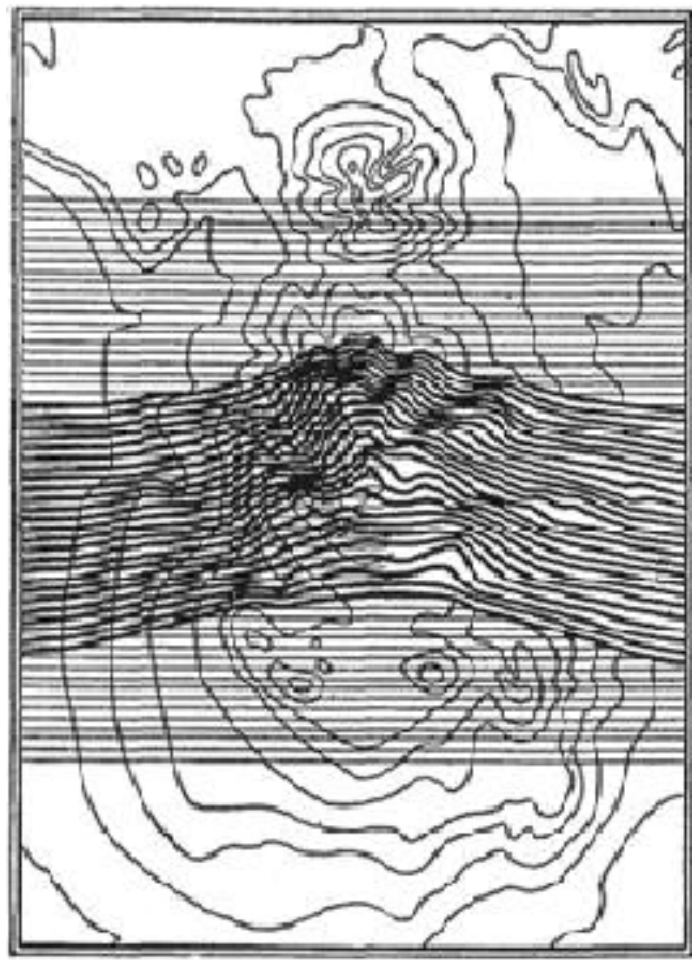

Figura 1. Curvas de nível em planta (visão vertical) e em perfil (visão obliqua baixa). Fonte: Kennelly (2002 apud Souza 2009)

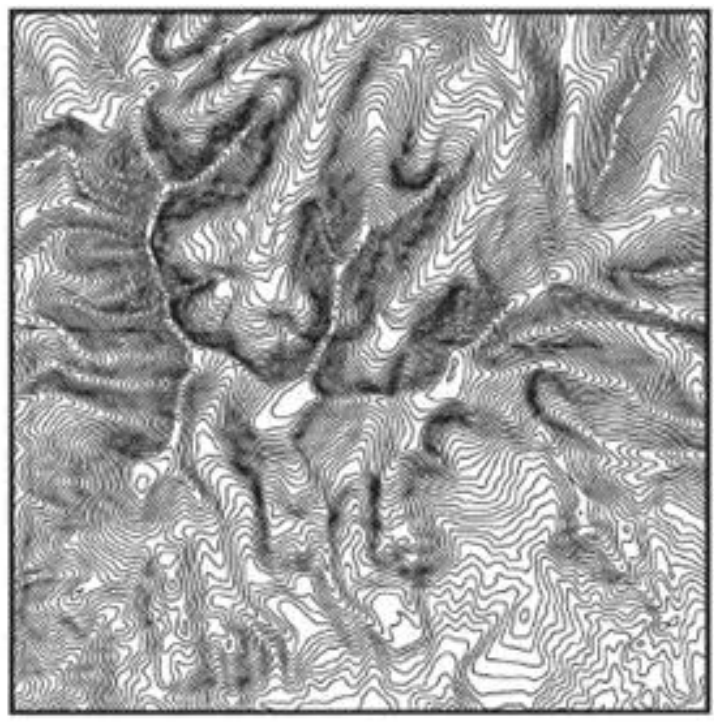

Figura 2. Curvas de nível em planta (visão vertical) com sombra para realçar os vales. Fonte: Kennelly (2002, apud Souza 2009)

nessa figura representa o relevo em uma sucessão de perfis topográficos, a partir das curvas de nível representadas no segundo plano. Já a Figura 2 refere-se a uma superfície de terreno, identificada a partir da interação das curvas de nível e da presença de sombra (áreas mais escuras), a qual dá à imagem bidimensional uma percepção tridimensional.

O estudante, ao observar as curvas de nível, deve ser capaz de realizar, mentalmente, a reconstituição do bi para o tridimensional - sólidos -, pela separação e identificação da extensão de cada curva, que se transformará em planos (Fig. 3). O exercício demanda a habilidade de conceber e de visualizar os vários planos sobrepostos - significantes -, com o auxilio dos números - altitude - que as curvas trazem. Logo, a combinação de planos, organizados em ordem crescente, da base para o topo, possibilita que o aluno relacione símbolos (linhas e números) e conceitos (curva de nível, relevo, formas) e visualizar (imaginar) a superfície do terreno representado. Embora pareça simples, essa relação se configura como de elevado grau de dificuldade para muitas pessoas, as quais não conseguem decodificar nem entender a relação entre os símbolos. De acordo com Clark et al. (2004), há pessoas que ainda não conseguem perceber a relação existente entre o espaçamento entre as curvas e a declividade do terreno. Portanto, atividades práticas com a transposição da imagem bidimensional para a tridimensional, por meio da elaboração de planos de superfícies altimétricas (curvas de nível), possibilitam ao aluno superar 


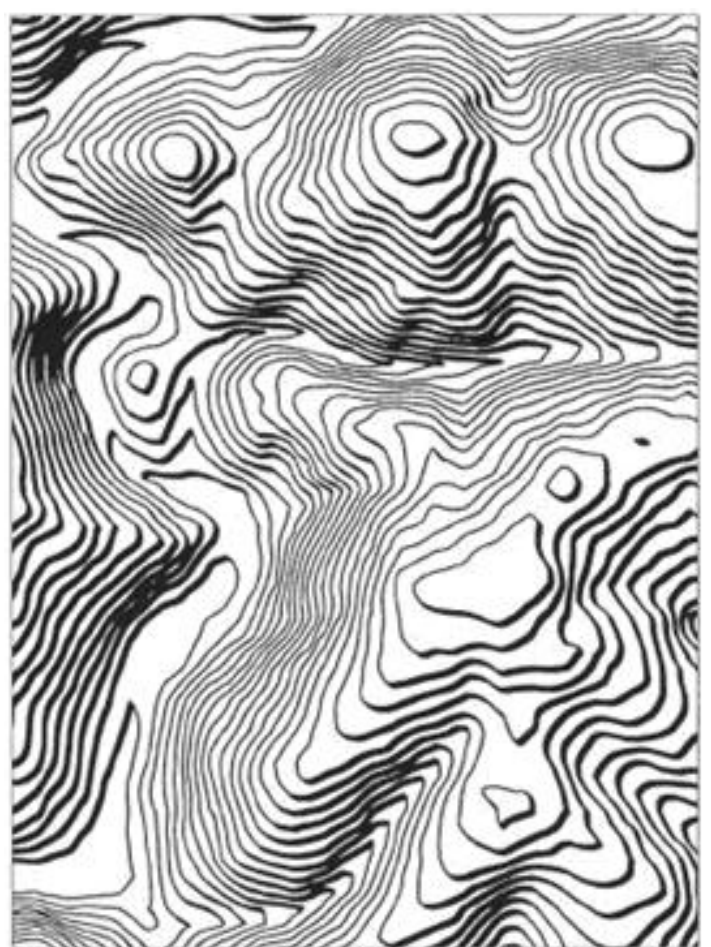

Figura 3. Mapa de uma porção sul de Haifa (Israel) Fonte: Yoeli (1983, fig. 18, p. 109 apud Kennelly 2002, p. 433)

o equívoco e as dificuldades de associação entre o espaçamento das curvas e o aspecto do relevo (Souza 2009).

Quando o observador entende o que significam o espaçamento entre as curvas e as próprias curvas presentes no mapa (texto não verbal), há leitura desses significantes e dos seus significados, bem como se pode concretizar a expressão verbal (oral ou escrita) do conceito desses planos de superfície. De acordo com Souza (2003),

A transposição da imagem em planta (bidimensional) para a imagem em volume (tridimensional) demanda do observador a habilidade de perceber o posicionamento das linhas no espaço (X, Y, Z) e não mais na base plana. Para isso, é necessário ao observador criar em sua mente a geometria tridimensional da imagem. Esta fica mais difícil quando se trabalha com formas cujas superfícies e estruturas não são retilíneas como o cubo, por exemplo e sim irregulares como a topografia de áreas dissecadas a partir da erosão diferencial. Nesse caso se tem dois obstáculos a serem superados. O primeiro o de decodificar e visualizar a posição das linhas no espaço; o segundo o de entender a sinuosidade das linhas como expressão da dissecação do modelado (Souza 2003, p.161).

Nota-se que esse exercício mental demanda do sujeito várias habilidades combinadas: a da decodi- ficação do símbolo, como reconhecimento da linguagem gráfica não verbal; a da relação da estrutura e organização das curvas de nível com a materialização do volume no espaço; a do conhecimento conceitual específico (erosão) e a da expressão da forma na linguagem imagética.

Para Van Hiele (1986), as estruturas dos elementos, que compõem o espaço, estão presentes nas visões de mundo e na organização da cognição, ou seja, o arranjo desses elementos apresenta alguma estrutura que pode ser captada, logo, existente no mundo visível, real, que Van Hiele chamou de Mundo 1. Quando a estrutura é significativa, ou seja, captada e mesmo que não descrita verbalmente, mas percebida, está no Mundo 2, da mente, da cognição e do pensamento (Van Hiele 1986). Essa estrutura concebida a partir da interação do Mundo 1 com o Mundo 2, por meio da percepção, possivelmente é o que Piaget e Inhelder (1993) denominam de intuição.

Segundo Van Hiele (1986),

[...] a criação de estruturas mentais envolveria dois atos de pensamento distintos. No primeiro deles, ao se deparar com uma estrutura na forma de desenhos, por exemplo, uma pessoa poderia evocar estruturas visuais, não verdadeiramente matemáticas. Mas, ao analisar as figuras, seria possível abstrair e eliminar certo número de qualidades e então as figuras seriam vistas e identificadas de outras maneiras. Novas estruturas mentais seriam, portanto, formadas. Um segundo ato do pensamento seria a classificação de estruturas inter-relacionadas. Se o aluno conseguisse estabelecer vários critérios para classificação de estruturas, os próprios critérios ou princípios seriam uma nova estrutura. Esse novo processo de pensamento estaria então em um nível mais elevado (Van Hiele 1986 apud Viana 2000, p. 38).

A linha de pensamento de Van Hiele (1986) refere-se ao entendimento geométrico de figuras planas ou sólidas. Para esse matemático, identificar, analisar e interpretar geométricos, seja no real, seja na representação, compreende a interação dos mundos 1 e 2, em diferentes níveis de entendimento, do mais simples ao mais complexo. Portanto, Van Hielle (1986) propõe cinco níveis, como um modelo de entendimento geométrico: (a) "visualização" (reconhecimento ou nível básico), (b) "análise", (c) "dedução informal" (ordenação, síntese ou abstração), (d) "dedução" e (e) "rigor". Os níveis descrevem características do processo 
de pensamento com a geometria (Crowler 1994).

Apesar de serem campos diferentes do conhecimento, um da Matemática e outro das Geociências, a questão do pensamento e da interação mundos 1 e 2 se processam de maneira semelhante. Quando ocorre a identificação da forma, pode-se dizer que nessa relação sujeito-objeto houve a percepção do segundo pelo primeiro. A percepção significa a seleção de um objeto entre inúmeros e múltiplos outros (Oliveira 1977), devido ao reconhecimento de seu significado, de seus atributos e da estrutura que o identifica (Souza 2009). Quando a forma é descrita e abordada, individualmente, em uma representação, é abstraída do espaço, do todo, e "coisificada" como um objeto. Nesse momento, seu aspecto geométrico pode ajudar a identificá-la, uma vez que, na ciência, utilizam-se das categorias e nomenclaturas para organizar os objetos de investigação em tipos, no caso das geociências o geométrico é uma delas.

\section{Conhecimentos e dificuldades dos graduandos com representação espacial}

Entre os vários materiais produzidos pelos estudantes de graduação (trabalhos práticos, provas e relatórios) e coletados por Souza (2009), utilizaram-se as produções dos sujeitos da pesquisa referentes a trabalho prático com cartas topográficas, na escala 1:250.000. Essas produções constituíram fonte de informação para a análise do desempenho dos alunos quanto à leitura e representação espacial.

Para a análise, estabeleceram-se os seguintes parâmetros qualitativos:

1. Correspondência de configuração - que significa articulação dos símbolos no mapa e o arranjo espacial das formas no contexto real representado na carta (Liben et al. 2002 apud Ishikawa e Kastens 2005);

2. Identificação de formas e padrões em um todo complexo;

3. Clareza nas definições das formas e seu contexto

4. Relação definição e representação;

5. Organização do desenho (croqui) no papel

Para cada parâmetro qualitativo adotou-se o critério de peso, a saber: peso (2) - o parâmetro se aplica; peso (1) - o parâmetro se aplica com restrições; peso (0) - o parâmetro não se aplica. A somatória dos pesos possibilitou analisar cada trabalho e compará-los entre si segundo critérios quantitativos e qualitativos.

O trabalho prático com carta topográfica ocorreu em grupo, com 4 a 5 componentes, organizados em seis grupos (A, B, C, D, E e F). Cada grupo recebeu uma carta topográfica da região da Groenlândia, escala 1:250.000, com a tarefa de identificar, descrever e representar as formas de relevo, resultantes de processos morfoclimáticos comuns em domínios glacial e periglacial e presentes na carta. A atividade foi proposta pelo docente responsável pela disciplina como recurso mediador da relação processos e formas em diferentes ambientes climáticos e a representação cartográfica das respectivas formas. Para isso, era necessário que o estudante pensasse na relação forma, dimensão espacial real, escala cartográfica e representação (desenho).

Por meio das cartas topográficas, de várias porções do território da Groelândia, os grupos de alunos identificaram diferentes formas de relevo de origem erosional, como os Fiords e os Circus e as formas de acumulação, como morainas e deltas. Para fins de análise e comparação, neste texto, consideraram-se apenas as representações, dos seis grupos, referentes às formas de Fiords e Morainas.

As representações revelaram o desempenho e as dificuldades dos grupos segundo os critérios anteriormente estabelecidos. O resultado quantitativo encontra-se expresso na Tabela 1, enquanto o qualitativo é apresentado nos parágrafos seguintes.

Com a análise da Tabela 1 e dos aspectos qualitativos considerados, verifica-se que entre os seis grupos estudados foram identificados dois deles (grupos B e D) que apresentaram dificuldades de natureza cartográfica e de representação, que se desdobram em dificuldades referentes a normas técnicas. As normas técnicas se referem aos elementos externos que devem sempre estar contidos em um mapa, como, por exemplo, as coordenadas geográficas, que permitem localizar a porção estudada na carta original e a escala cartográfica. Não basta apenas identificar as formas observadas, é necessário indicar onde elas ocorrem no espaço geográfico estudado e qual a extensão das mesmas. A ausência dos elementos, que permitem localizar a área mapeada e calcular a dimensão espacial das formas de relevo ou da superfície do terreno, mostra a falta de atenção e de valorização da linguagem cartográfica durante a representação e o raciocínio geomorfológico.

Apesar de apresentar conhecimento satisfatório dos conceitos e das formas de relevo estudados em 
Tabela 1. Desempenho com as representações bidimensionais (carta topográfica) (Fonte: Souza 2009)

\section{Mapas e grupos}

Representação

Mapa A Mapa B Mapa C Mapa D $\quad$ Mapa E Mapa F

\begin{tabular}{|c|c|c|c|c|c|c|}
\hline Elementos do mapa e organização & 1 & 0 & 2 & 0 & 1 & 1 \\
\hline Correspondência Configuracional & 2 & 0 & 2 & 0 & 2 & 2 \\
\hline $\begin{array}{l}\text { Identificação de formas e padrões em um } \\
\text { todo complexo }\end{array}$ & 2 & 2 & 2 & 1 & 2 & 2 \\
\hline Parâmetros conteúdo & Mapa A & Mapa B & Mapa C & Mapa D & Mapa E & Mapa F \\
\hline Clareza nas definições das formas & 2 & 2 & 2 & 1 & 0 & 1 \\
\hline $\begin{array}{l}\text { Relação identificação das formas e } \\
\text { representação }\end{array}$ & 2 & 2 & 2 & 1 & 1 & 2 \\
\hline TOTAL PONTOS (10) & 9 & 6 & 10 & 3 & 6 & 8 \\
\hline
\end{tabular}

geomorfologia, o Grupo B revelou deficiência na representação cartográfica (Fig. 4), enquanto os integrantes do Grupo D apresentaram conhecimento insatisfatório, tanto dos conceitos, quanto da representação e da visualização espacial (Fig. 5).

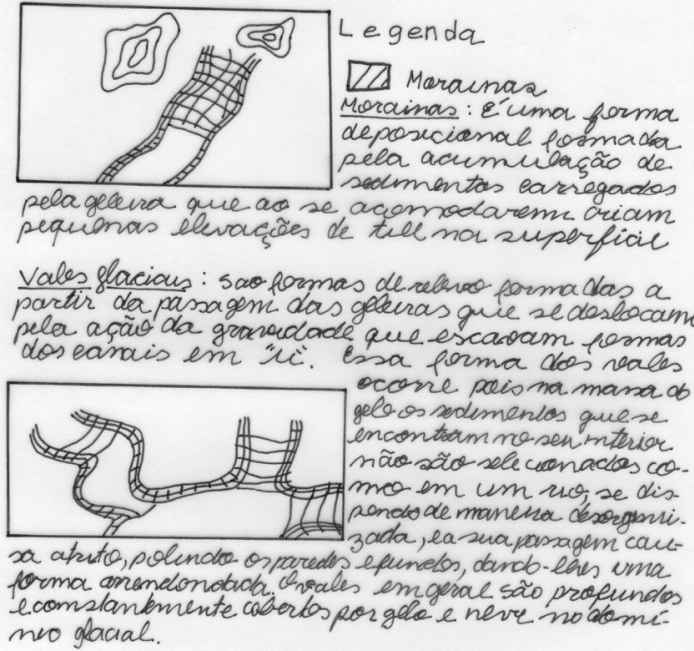

Figura 4. Representação do Grupo B (Fonte: Souza 2009)

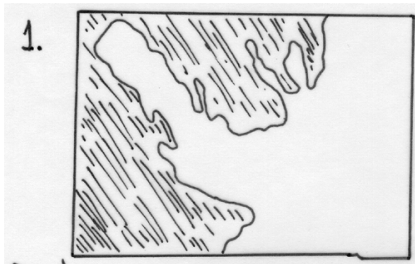

f wordos Tratam-re de vales glaciars que a serem invadidos pelo-mac, resultam en uma marfolegia en farma de "U", davide a açäo da

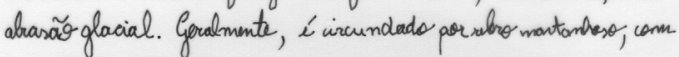
predomíno de escarpas.

Figura 5. Representação do grupo D (Fonte: Souza 2009)

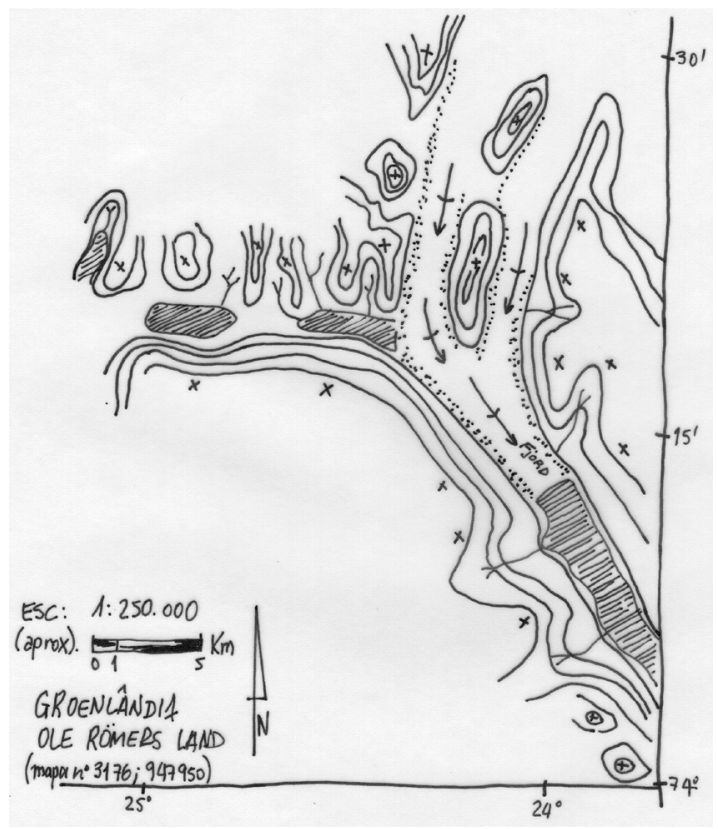

Figura 6. Representação do Grupo C (Fonte: Souza 2009)

Os sujeitos que compõem o Grupo D (Fig. 5) não empregaram o recurso da curva de nível, que permite a visualização das formas em 3D (Fig. 4), apenas representaram as formas a partir de seu possível contorno, diferentemente do Grupo C (Fig. 6).

Além disso, os alunos do Grupo D não revelaram habilidade para representar em desenhos, mesmo utilizando cartas como referência. A elaboração de um croqui demanda a capacidade de selecionar o objeto de interesse, evidenciá-lo e colocar em segundo plano as demais informações que ajudam a evidenciar o seu objeto. Além disso, é necessário escolher um símbolo como recurso para dar feição à forma que se deseja representar. 
Esse grupo escolheu linhas e hachuras.

Além das representações insatisfatórias, as definições registradas pelo Grupo D são genéricas, faltam termos que complementem as ideias apresentadas e mostram falta de clareza dos conceitos de formas de relevo, processos geomorfológicos e condicionantes, conforme se pode verificar nesta definição:

Fiords: "trata-se" de vales glaciais que ao serem invadidos pelo mar resultam em uma morfologia em forma de U, devido à ação da abrasão glacial. Geralmente, são circundados por relevo montanhoso, com predomínio de escarpas.

A generalização do desenho reforça a ideia da simplicidade e confusão da definição. Se não há clareza quanto à sequência de formas e suas respectivas gêneses (considerando processos, agentes, condicionantes e escalas temporal e espacial), fazer a síntese do que se pede torna-se mais difícil, por consequência, em especial quando combinada à pouca habilidade gráfica.

Já o Grupo B, apesar da dificuldade com a representação, mostrou definições satisfatórias para as formas identificadas. A habilidade para se apresentar uma boa definição difere da representação imagética. Enquanto esta demanda habilidade de percepção, traços e visualização espacial, a outra demanda conhecimento dos termos e conceitos. O fato parece ter ocorrido, também, com o Grupo E, porém em situação inversa. Os componentes mostraram desempenho satisfatório com a representação, mas insatisfatório com as definições. No caso do Grupo E, os componentes se limitaram a escrever palavras sobre a forma (Fig. 7), sem explicá-las quanto à gênese, como ocorreu com os demais grupos, ou ainda, não escreveram nada. Portanto, comparando a produção dos grupos, o Grupo E obteve pesos inferiores nos parâmetros conteúdo.

Segundo Pino (1996), a representação realizada pelo adulto resulta da integração da percepção sensível e do conhecimento. Apesar dessa integração, o trabalho com a representação de um determinado fenômeno no espaço implica em "lidar com as contradições inerentes à própria natureza da percepção: o único e o múltiplo; a parte e o todo; o idêntico e o diferente; o mesmo e o outro; o aqui e o alhures, etc." (Pino 1996, p. 65). A escolha de uma ou de outra dessas contradições, dependerá do conhecimento teórico e da habilidade gráfica que se tem.

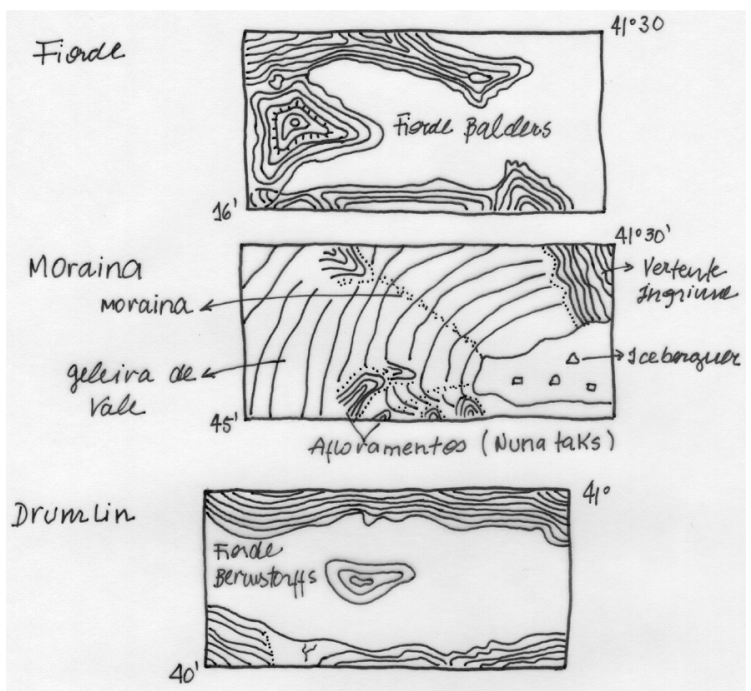

Figura 7. Representação do Grupo E (Fonte: Souza 2009)

Entre as representações gráficas dos grupos B e D, é possível verificar que, das contradições apontadas por Pino (1996), os alunos escolheram, nas ilustrações produzidas em sala de aula, a parte dentro do todo, quando realizaram os desenhos das formas de maneira isolada, ou seja, como uma parte recortada do todo. Consequentemente a representação deixou em aberto o significado desejado pelo sujeito que desenhou, uma vez que se encontra fora de um contexto aos olhos de um segundo leitor.

Ainda, segundo Pino (1996, p. 67), "ao nomear as coisas, o homem confere-lhes uma nova existência que as torna inteligíveis e comunicáveis". Apesar disso, quando se fala, também, de comunicação por meio de linguagem imagética, a habilidade gráfica torna-se importante, mas pode ser dificultada quando carece de conteúdo, como pode ser verificado no trabalho do Grupo D, cujo resultado é considerado insatisfatório.

$\mathrm{Na}$ combinação representação e conteúdo, os grupos A, C e F obtiveram valores entre 8 e 10 . Esses grupos foram os únicos que apresentaram a maioria dos requisitos esperados, tais como os principais elementos externos do mapa (título, orientação e escala cartográfica), a qualidade dos traços e das representações (em pelo menos uma de suas representações), além da relação representação, nomenclaturas, definições e texto. Os trabalhos são bem organizados, compostos por croquis seguidos de textos descritivos.

Devido à natureza da atividade - identificar na carta topográfica, por meio de desenho em planta, formas de relevo comuns nos ambientes glacial e periglacial, os grupos preocuparam-se com a orien- 
tação e a identificação da localização do desenho na carta. Para isso, registraram as coordenadas geográficas, como recurso para relacionar o croqui e a porção do mapa considerada. Os grupos conseguiram identificar e contextualizar formas mapeáveis na escala considerada (1:250.000) por meio de traços equivalentes às curvas de nível (Mapa $\mathrm{C}$ ) combinados com sombras (Mapa A) e setas indicativas de fluxos (Mapa C), Fig. 6.

Considerando-se os níveis de entendimento geométrico de Van Hiele (1986), com base na ideia de estruturas que podem ser reconhecidas, relacionadas e classificadas, pode-se pensar que com a visualização espacial das formas de relevo ocorra processo semelhante. Ou seja, se o aluno concebe a forma por seus atributos estéticos e organização interna (estrutura e litologia) por meio de representação visual (carta topográfica e/ou blocos-diagramas), será capaz de, durante o mapeamento e o trabalho em campo, identificar os atributos externos e internos que, quando inter-relacionados, permitem a representação mental. Logo, será capaz de reconhecer a forma na representação e no real, auxiliado pela percepção do objeto em um contexto.

De acordo com Van Hiele (1986), identificar a figura, bem como suas partes, seus atributos e a relação das mesmas na estrutura do desenho e da forma compreende o segundo nível de entendimento geométrico, ou seja, o de análise. Nessa atividade o aluno deve utilizar, também, a habilidade espacial como a de visualização e de rotação para perceber cada possível parte da forma exposta ou não.

Para identificar uma forma ou unidade de relevo é necessário, inicialmente, que o sujeito a conheça e entenda seu significado na Geomorfologia. E, ainda, conhecer seu aspecto fisiográfico, sua escala geográfica de ocorrência, sua escala geomorfológica (relação escala espacial e temporal) e seus atributos internos e externos. Partindo-se do princípio de que o sujeito conhece o conteúdo, acredita-se então que ele tem clareza do significado geomorfológico da forma de relevo a ser, inicialmente, identificada na imagem. Caso se trate de uma carta topográfica, o aluno deve ser capaz de decodificar os símbolos e ler os conteúdos geomorfológicos.

Nota-se, portanto, que a representação e a visualização compreendem a interação de diversas habilidades e conhecimentos, que se interagem a partir da dimensão externa e interna inerente aos seres humanos. Portanto, por mais simples que a representação seja, expressa a compreensão e a leitura "das coisas" do mundo pela percepção (codificação e decodificação), a visualização e o pensamento e conhecimento humano.

Em Geomorfologia pode-se dizer que as habilidades, para possíveis competências, compreendem, entre outros aspectos, o saber fazer: (a) a identificação das formas de relevo, no trabalho em campo e nas diferentes linguagens; (b) a relação de processos geomorfológicos/formas/escalas espacial e temporal; (c) a análise das formas, segundo um arcabouço teórico; (d) a interpretação do relevo, à luz da visão integrada, sistêmica e dinâmica, independente das escalas espacial e temporal e (e) a representação do fenômeno geomorfológico considerado (Souza 2009).

Cada uma dessas habilidades demanda outros conhecimentos, que podem ser referentes a conteúdos específicos, a conceitos, a normas e regras e a noções espaciais, como percepção, orientação e representação. Por exemplo, o saber identificar algo implica conhecer os atributos e a nomenclatura que identificam um determinado objeto socialmente concebido; para o saber relacionar é importante conhecer os diferentes objetos, alvos de observação, em seu aspecto físico (atributos), dinâmico e funcional e o nível e tipo de interação dos objetos.

Pode acontecer de o sujeito saber identificar uma forma e um processo, mas não saber analisá-los nem interpretá-los, porque ficou condicionado a reconhecer e reproduzir modelos, com base nos seus atributos visíveis, concretos e objetivos, construídos a partir da dimensão estática do relevo. Diante disso, verifica-se que conteúdos de outros campos do saber, como o da cartografia, são fundamentais para o "saber fazer" em Geomorfologia. Para o sujeito realizar a identificação das formas de relevo, em uma carta topográfica, deve antes, ser capaz de decodificar os símbolos comuns na linguagem cartográfica, bem como conhecer conceitualmente as formas representadas.

\section{Considerações Finais}

Pode-se dizer que, ao pensar uma forma de relevo e sua gênese elabora-se uma construção mental que leva em consideração vários aspectos como delimitação, forma, descrição, processos e produtos, a partir da associação espaço, tempo, conceitos e linguagens, a fim de caracterizar o fato, analisá-lo e interpretá-lo à luz de uma teoria ou modelo de representação.

No ensino de Geomorfologia, geralmente o professor utiliza materiais visuais, via lousa, 
datashow e trabalho de campo, que são fontes imagéticas ricas em representações. Entretanto, a boa qualidade do material utilizado no ensino não implica, necessariamente, a aprendizagem do aluno. A aprendizagem depende de vários aspectos, entre eles o da cognição combinada com habilidades específicas com imagens, como a da visualização espacial, na segunda e na terceira dimensão. Sabe-se que o procedimento de levantar as características fisiográficas e a localização espacial das formas de relevo não significa pensar e fazer Geomorfologia, mas significa um procedimento e uma habilidade básica e necessária no processo para a interpretação geomorfológica. Sem conseguir identificar, visualizar e entender as formas resultantes de diferentes processos geomorfológicos e geológicos, o discente apresentará maiores dificuldades com os conteúdos se comparados com os alunos que apresentam habilidades satisfatórias.

O saber fazer a leitura e aplicação das imagens, como habilidades que demandam visualização e representação espacial, são construídas ao longo da vida e da formação escolar e/ou universitária. Portanto, durante o ensino de Geomorfologia cabe ao professor estar atento a essas habilidades nos alunos, para que possam ser acrescentadas atividades com geometria e poliedros, por exemplo, a fim de possibilitar que os alunos superem possíveis dificuldades com a habilidade espacial.

O exercício da docência coloca o professor em posição privilegiada para observação e percepção do conhecimento e das dificuldades apresentadas pelos discentes, referentes aos conteúdos ministrados por ele. Ciente disso, ser um professor é muito mais do que ensinar conteúdos, mas estar atento à aprendizagem dos alunos e à possível origem de suas dificuldades. Ensinar Geomorfologia não foge disso e implica que o professor pergunte-se continuamente: como estão os meus alunos, na condição de sujeitos, em relação à interação sujeito-conteúdos-habilidades fundamentais?

\section{Referências Bibliográficas}

Almeida R.D.de, Passini E.Y. 1994. O espaço geográfico: ensino e representação. São Paulo: Contexto.

Clark D., Reynolds S., Lemanowski V., Stiles T., Purzer S.Y. 2004. Interpreting topographic maps: Strategies and assumptions of university students, Paper presented at the annual meeting of the National Association for Research in Science Teaching, Vancouver, Canada.
Ishikawa T., Kastens K.A. 2005. Why some students have trouble with maps and other spatial representations. J. Geosc. Educ., 53(2):184-197.

Kali Y., Orion N. 1996. Spatial abilities of High-school students in the perception of Geologic structures. J. Research in Science Teaching, 33(4):369-391.

Kennelly P.J. 2002. Gis applications to historical cartographic methods to improve the understanding and visualization of contours. J. Geosc. Educ. $\mathbf{5 0}(4): 428-436$.

Libarkin J.C., Brick C. 2002. Research methodologies in science education: visualization and the geosciences. J. Geosc. Educ., 50(4):449-455.

Liben L.S., Kastens, K. A., Stevenson, L.M. 2002. Real-word knowledge through real-world maps: a developmental guide for navigating the educational terrain. Development Review, 22: 267-322.

Liben L.S., Downs R.M. 2005. Understanding person-space-map relations: cartographic and developmental perspectives. Developmental Psychology, 29: 739-752.

Oliveira L.de. 1977. Estudo metodológico e cognitivo do mapa. 1997. Rio Claro: Univ. Estadual Paulista, IGCE. 234p. (Tese Livre docência).

Piaget J., Inhelder B. 1993. A representação do espaço na criança. Porto Alegre: Artes Médicas.

Pino A. 1996. A categoria de "Espaço" em Psicologia. In: Miguel A., Zamboni E. 1996. Representação do espaço: multidisciplinaridade na educação. Campinas: Autores Associados. p. 51-68.

Pohl V. 1994. Visualizando o espaço tridimensional pela construção de poliedros. In: Lindquist M.M., Shulte A.P. Aprendendo e ensinando geometria. Trad. Hygino H. Domingues. São Paulo: Atual. p.178-190.

Rhoads B.L., Thorn C.E. 1996. The Scientifid Nature of Geomorphology. England: John Wiley \& Sons. $481 \mathrm{p}$.

Santaella L., Nöth W. 1999. Imagem: cognição, semiótica, mídia. São Paulo: Iluminuras.193p.

Souza C.J.O. 2003. Ensino de Geomorfologia contextualizado na transposição didática. In: Simp. Geogr. Física Aplic., 10, 2003, Rio de Janeiro. Anais... Rio de Janeiro: UERJ, nov. 2003. p. 156-165.

Souza C.J.O. 2009. Geomorfologia no ensino superior: difícil, mas interessante! por quê? uma discussão a partir dos conhecimentos e das dificuldades entre graduandos de geografia - IGC/UFMG. Belo Horizonte: Inst. Geoc. Univ. Fed. Minas Gerais. (Tese Dout.).

Van H.P.M. 1986. Structure and Insight. A Theory of Mathematics Education, Orlando: Acad. Press. 246 p. 